\title{
Pseudonyms as carriers of contextualised threat in 19th- century Irish English threatening notices
}

DOI:

10.1075/eww.00059.pet

\section{Document Version}

Accepted author manuscript

Link to publication record in Manchester Research Explorer

\section{Citation for published version (APA):}

Van Hattum, M., \& Peters, A. (2021). Pseudonyms as carriers of contextualised threat in 19th-century Irish English threatening notices. English World-Wide, 42(1), 29-53. https://doi.org/10.1075/eww.00059.pet

\section{Published in:}

English World-Wide

\section{Citing this paper}

Please note that where the full-text provided on Manchester Research Explorer is the Author Accepted Manuscript or Proof version this may differ from the final Published version. If citing, it is advised that you check and use the publisher's definitive version.

\section{General rights}

Copyright and moral rights for the publications made accessible in the Research Explorer are retained by the authors and/or other copyright owners and it is a condition of accessing publications that users recognise and abide by the legal requirements associated with these rights.

\section{Takedown policy}

If you believe that this document breaches copyright please refer to the University of Manchester's Takedown Procedures [http://man.ac.uk/04Y6Bo] or contact uml.scholarlycommunications@manchester.ac.uk providing relevant details, so we can investigate your claim.

\section{OPEN ACCESS}




\title{
Pseudonyms as carriers of contextualised threat in 19th-century Irish English threatening notices
}

\author{
Arne Peters (University of Potsdam) \& \\ Marije van Hattum (The University of Manchester)
}

This paper explores functions of pseudonyms in written threatening communication from a cognitive sociolinguistic perspective. It addresses the semantic domains present in pseudonyms in a corpus of 19th-century Irish English threatening notices and their cognitive functions in the construction of both cultural-contextualised threat and the threatener's identity. We identify eight semantic domains that are accessed recurrently in order to create threat. Contributing to the notion of threat involves menacing war, violence, darkness and perdition directly, while also constructing a certain persona for the threatener that highlights their motivation, moral superiority, historical, local and circumstantial expertise, and their physical and mental aptitude. We argue that pseudonyms contribute to the deontic force of the threat by accessing cultural categories and schemas as well as conceptual metaphors and metonymies. Finally, we suggest that pseudonyms function as post-positioned semantic frame setters, providing a cognitive lens through which the entire threatening notice must be interpreted.

Keywords: pseudonyms, threatening communication, Irish English, persona construction, sociocultural cognition, context-specificity, post-positioned semantic frame setters

\section{Introduction}

Bonapart is our friend - B-Ready (Slane, 30/05/1803, Meath)

Nowadays, receiving a note with the words above in the post might raise some eyebrows, but will hardly be cause for great alarm. In early 19th-century Ireland, however, when this notice was posted and forwarded to the authorities in Dublin Castle, it was certainly perceived as threatening. Additionally, in the early 21 st century when it was included in a collection of 529 Pre-Famine Irish English threatening letters (Gibbons 2004: 46), it was still deemed an authentic representative of 19th-century Irish English threatening communication. This does not only lead to the more general question of which elements constitute a threat from a linguistic perspective, but also to the question of the particular role pseudonyms such as B-Ready play in contributing to the deontic force of the threat. Hence, the present paper will study the linguistic forms and cognitive-cultural functions that pseudonyms have in a collection of 19th-century Irish English threatening communication.

Linguistic research on threatening communication started with the discussion of threatening as a speech act and aimed to distinguish threats from other speech acts such as 
promising or warning (e.g. Searle 1975; Fraser 1998; Blanco Salgueiro 2010). Much research on threatening communication to date has focussed on the assessment of the severity of the threat through the identification of social, behavioural and linguistic factors (e.g. Dietz et al. 1991; Smith 2008). Other research has investigated the legal definition of threat and how it differs from the linguistic definition discussed in early research on threatening as a speech act (e.g. Solan and Tiersma 2005). The studies mentioned above, however, generally adopted largely philosophical approaches, relying on introspective reflections and qualitative discussion of mostly fabricated examples (see Muschalik 2018: 9).

The past decade has seen research that sought to remedy this lack of empirical studies on linguistic aspects of threatening communication. A handful of corpus-based approaches have been produced by researchers such as Gales (2011), Muschalik (2018) and Nini (2017), all of which, however, are based on late 20th-century American English. The only study to date which makes use of a dataset other than American English is Van Hattum (2017), which explores the linguistic expression of identity in late 19th-century Irish English threatening communication. However, none of these studies provided an in-depth analysis of the role pseudonyms play in cognitively framing and culturally conceptualising a threat, leaving unexplored the range of semiotic choices that threateners make when constructing a culturally and socially contextualised persona in order to create the greatest possible threat (cf. Brinkman 2004; Newell 2010).

The present paper adds to the growing body of empirical research on threats by placing particular emphasis on the functions of pseudonyms in written threatening communication. Since pseudonyms are argued to be constructed within a cultural naming system (e.g. Brinkman 2004; Livia 2004), the present analysis is conducted from a cultural linguistic and cognitive sociolinguistic perspective with a focus on sociocultural contextualisation of language use (e.g. Wolf and Polzenhagen 2009, 2017; Sharifian 2015; Peters 2017). It is based on pseudonyms found in the Threatening Notices Corpus (TNC), which is a collection of 19th-century Irish English threatening notices (cf. Section 3.1). This dataset is of interest because it is a unique source of historical threatening communication, the like of which has not been studied for any other variety of English. In representing 19th-century Irish English, this dataset adds to counterbalancing the dominance of research on present-day American English in threatening communication research by focussing on a variety of English that differs both regionally and temporally. At the same time, Irish English is highly suitable for a cognitive sociolinguistic analysis because of intensive and persisting language contact with Irish Gaelic, which was at its height during the 19th century (see e.g. Kallen 2017: 30-38). The intensive and largely unguided collective acquisition of English during this time led to a rapid language shift from Irish Gaelic to English (Ó Cuiv 1986; Hickey 2007; Kallen 2017), allowing for the transfer of traditional Irish Gaelic sociocultural conceptual systems into English (Peters 2017: 128-9). Thus, this paper not only analyses the different functions of pseudonyms in 19th-century Irish English threatening notices, it also discusses how these functions are embedded from a sociocultural-cognitive point of view. This means that in addition to what we claim are generalisable ways in which pseudonyms contribute to the overall conceptualisation of a threat, we also explore cognitive elements that can only be understood in 
sociocultural context, i.e. from a contemporary, circumstantial, local and/or socioculturally informed point of view.

\section{Theoretical framework}

\subsection{A cognitive sociolinguistic perspective on threat}

Verbal and non-verbal (e.g. I will cut off your finger vs. sending someone a cut-off finger) as well as direct and indirect expressions of threat (I will kill you vs. isn't life is sweet) need to conform to cultural and social semiotic norms and conventions in order to be perceived as threats (Walton 2000: 111). Moreover, the act of threatening can be seen as the outcome of one form of interpersonal negotiation of meaning between two social actors (Gales 2011: 29) in "a complex network of contextual relationships, and not just the private mental states of those involved" (Blanco Salgueiro 2010: 215). Thus, threats must be regarded as being enregistered groupspecifically in different communities of practice (Gales 2011: 28) and as being "socially recognised as indexical of speaker attributes by a population of language users" (Agha 2005: 38, qtd. in Gales 2011: 28).

These pragmatic observations can be translated into cognitive sociolinguistic terms by means of the notion of sociocultural cognition, i.e. "patterns of distributed knowledge across the cultural group [...] [that] embody group-level cognitive systems such as worldviews" (Sharifian 2011: 5), but also common experiences and memories shared by cultural (and in fact, social) groups. If the act of threatening, as an outcome of the interpersonal negotiation of meaning between the threatener(s) and their victim(s), is to be successful, both the conditions and the measures of the threat must be accessible to the negotiators, either as active or at least as passive sociocultural semiotic knowledge from an in-group and/or an informed out-group perspective. The process of creating threat in the TNC can be regarded as only being fully functional because both the sender(s) and the recipient(s) of the notes belong to the same social/cultural group and participate in a shared social/cultural reality. In this reality, both sides assign contextualised meaning to the world surrounding them in a similar way and this intracultural organisation of thought comes to light in the use of language (Sharifian 2015: 516).

Shared cognitive processing of reality produces a common set of sociocultural categories and schemas, i.e. categorisations of objects, events, and emotions that provide a basic semantic framework for the constituents of a given cultural repertoire (categories) and social, emotional, and stylistic evaluations, as well as knowledge about which events, sub-events, participants, pragmatic necessities, etc. are associated with the category (schemas) (see Peters 2017: 131).

Any analysis of socioculturally embedded categories and schemas is likely to also produce insights into conceptual metaphors and conceptual metonymies, which involve complex cognitive processes of systematic inter- and intra-domain mappings respectively that enable the understanding of and/or referencing to certain (frequently more abstract) semantic entities (e.g. 
Lakoff and Johnson 1980: 35-37; Kövecses 2015: 1-15). While in conceptual metaphors systematic correspondences between a source and a target domain allow for the "mapping" of one domain onto the other, conceptual metonymies use one entity of a domain in order to refer to another entity of the same domain (e.g. Lakoff and Johnson 1980: 35-37; Kövecses and Radden 1998: 62-71). A thorough analysis of individual linguistic metaphorical and metonymic expressions as well as their underlying conceptual metaphors and metonymies is likely to produce insights into a speech community's intracultural/contextualised organisation of thought and meaning, i.e. their sociocultural cognition, just as much as the analysis of underlying categorisations and schematisations. In the process of creating threat, sociocultural categories and schemas as well as conceptual metaphors and metonymies are accessed and utilised in order to create the most effective instances of threat. The analysis below will show how exactly pseudonyms in the TNC access the sociocultural cognition of rural Irish English speakers of the 19th century in order to instil fear.

\subsection{Pseudonyms}

Maleej et al. (2016: 212) define pseudonymity as the "adoption of a name different from the one an individual has on his or her official identification card", thus making pseudonyms "names that differ from a person's original orthonym ('true name') and that are assumed for a particular purpose" (Room 2010: 3), such as anonymity (Guenther 2009; Maleej et al. 2016). However, Newell (2010: 11) contrasts pseudonymity and pure anonymity; the latter refers to "the voluntary condition of non-being" and the former to "the voluntary condition of being other". The distinction between pure anonymity and pseudonymity suggests pseudonyms have the ability to create another identity. They provide the user with a level of authenticity and physical presence (Newell 2010: 13) and can be used to describe an aspect of their identity that the user wishes to emphasise (Felus 1990). Pseudonyms may signal or create affiliation with a specific social group or subculture (Aceto 2002), indicating the user's political interest and cultural affiliations (Newell 2010: 12). At times, pseudonyms can also preserve the memory of a deceased person or a previous user of that pseudonym (Brinkman 2010: 158). It is not only the name or the pseudonym that is then passed on, but also the identity or "spirit" that was attached to it, keeping that "spirit" alive through a generational cycle. All these functions aim to trigger a response or reaction from those exposed to the names (Newell 2010), e.g. in form of instilling fear in an enemy, boosting morale within one's own social group (Brinkman 2004), persuading someone to engage in a conversation or simply entertaining both the audience and themselves (Livia 2004).

Pseudonyms and the different identities they provide are generally constructed within a contextualised naming system, that is, they are embedded cognitively within the social and/or cultural context in which they are created and used, but not necessarily outside of it (Livia 2002; Brinkman 2004). The construction of a pseudonym, whether self-assigned or assigned by others, draws on the individual's personal history, social relations, geography, and the wider cultural, 
historical and political context (Brinkman 2004: 146). In a cognitive sociolinguistic approach to Serbian orthonyms, for example, Dobrić (2010: 139-140) notes that although contemporary semantics recognises that most orthonyms do not carry readily-accessible meaning, certain names seem to be, at least etymologically, highly culture- and context-specific as they draw from a number of semantic domains that are locally relevant, such as "local geographical areas, local gods or specific and different languages". Alongside these references to local (historical) realities, Dobrić (2010: 140) argues that the more generic and universal processes of metaphorisation and metonymic mapping are utilised to generate names.

In the TNC, the use of locally relevant, context-specific domains (e.g. Terry Alt Lord of County Carlow; Tipperary boy; Murty the Carder), metaphorisation (e.g. source domain MATERIAL: steel to target domain PERSON: Captain Steel) and metonymic mapping (e.g. ACTION OF A PERSON: 'the breaking of the neck' stands for the PERSON: Breakneck 'somebody who breaks necks') are three productive principles in the construction of pseudonyms that add different layers to the semiotic load of the threat and, hence, form part of our analysis.

\section{Data and methodology}

\subsection{The TNC}

In a century characterised by agrarian violence and "secret societies", the sending and receiving of threatening notices were a common occurrence (Whelehan 2012). These notices contained anonymous warnings or threats suspected to have been written by clandestine groups calling themselves, e.g. Carders, Rockites or Whiteboys. Some of these notices aimed to address private grievances or were sent as instruments of extortion. However, the vast majority of these notices constituted a form of social protest typically found in "any society which has crossed a certain threshold of literacy, in which forms of collective organized defence are weak, and in which individuals who can be identified as the organizers of protest are liable to immediate victimization" (Thompson 1975: 255), as was the case in Ireland at the time. These notices can thus be claimed to symbolise a form of social protest against tyrannical landlords and extortionary taxes as well as a resistance to ongoing changes in the agrarian sector, all of which exacerbated the already wretched economic conditions found throughout Ireland (Van Hattum 2017). The historian Stephen Randolph Gibbons collected 529 such notices, written between 1801 and 1845, from all over Ireland (Gibbons 2004). These, together with an additional 103 notices written between 1860 and 1872 collected by one of the authors in the National Archives Dublin, form the basis of the current version of a corpus of threatening notices.

The TNC is a corpus of authentic written materials; every notice in the corpus was deemed to be threatening by at least one member of contemporary society, as they were all forwarded to the Irish authorities for investigation. The later notices (1860-1872) were also classified as threatening by the authorities at Dublin Castle themselves as they were included as evidence for 
the prosecution of the presumed authors. The early notices were labelled threatening letters from a present-day perspective by Gibbons (2004). The fact that every text was deemed a piece of threatening communication by people outside of the present research is important, as it avoids circularity; if the materials are used to study what constitutes a threat, it is important that they were selected on the basis of contemporary perceptions of threat rather than the researchers' own preconceived notions (Jucker 2009; Muschalik 2018).

Altogether, the corpus comprises 632 texts, with a total of 86,676 orthographic units and covers a timespan from 1801 to 1872, with a gap between 1845 and 1860. All counties in Ireland are represented, though the vast majority of notices come from the provinces of Leinster (East) and Munster (South-West) while there are very few from Connacht (West) and Ulster (North).

\subsection{Data extraction and analysis}

Each of the texts in the corpus was checked for containing an orthonym, a pseudonym, or neither. In line with Gibbons (2004), when a reference to a name was found, either as part of the notice's signature (Example 1), or as an in-text reference (Example 2), the assumption was that this name was a pseudonym unless otherwise indicated in the contemporary commentary provided by the person who forwarded the letter to the media or the authorities. Since the sending of threatening notices was punishable by law, and the consequences very severe, particularly if such a notice could prove affiliation with a "secret society", we think it highly unlikely that senders would sign with their own, full orthonym. Indeed only one such instance was found, and in that case the author was immediately arrested (Example (1)) (see Gibbons 2004: 214). When texts contained no reference to a name for the author, either as (part of) the signature (Example (2)), or as an in-text reference (Example 3), they were coded as anonymous. In addition to the one text with an orthonym, we identified 232 anonymous texts and 399 pseudonymous texts, meaning that $63 \%$ of all notices in the corpus contain at least one pseudonym. Several texts, however, featured multiple pseudonyms, so the total number of pseudonyms investigated is 473 .

(1) Given under my hand this 2d of Febry 1822

Rock Mount Castle Capt Rock (Hawn, 02/02/1822, Tyrone)

(2) Notice from the true Rock There is a few acres in the townland of Ballanahaly which land jobbers are dusputeing it giving money and liquor to infamous villains [...] (Kildimo, 17/01/1823, Limerick)

As Example (2) indicates, the corpus contains a substantial degree of orthographic variation. For example, the pseudonym Rock could be spelled with $\langle\mathrm{c}\rangle,\langle\mathrm{ch}\rangle,\langle\mathrm{ck}\rangle$, and $\langle\mathrm{cke}\rangle$. In addition, titles such as Captain or General were often abbreviated to forms such as capt. or genl. To facilitate our analysis, the pseudonyms were all regularised for spelling and/or expanded from shortened forms. 
Each individual pseudonym was listed in an Excel file and initially coded for the variables text ID, year of writing, county of writing, affiliation other than pseudonym, and pre- or postmodifying descriptive phrase. By affiliation other than pseudonym we mean in-text references to the pseudonym of a third person/party, as in Example (3), where the author affiliates him- or herself with the social group that utilised the frequent pseudonym roary of the Hill, but does not selfidentify as Rory.

(3) $[\ldots]$ don't be astray of it in the least roary of the Hill is to be had [...] think on roary and his powder dry (unknown, 03/09/1869, unknown)

After the list of pseudonyms had been compiled, we examined it manually and applied a form of open coding, i.e. "the process of generating initial concepts from data" (Makoni 2016: 57), in order to identify the semantic values present in the pseudonyms. We applied double-blind coding, then compared the codes, discussed deviations and recoded if required. Each relevant, individual meaning-carrying element within a pseudonym was analysed separately, so that Terry Alt Lord of Carlow County was listed for the following semantic domains: historical person (Terry Alt), nobility (Lord), and Irish place name (Carlow County). Since this left us with a high number of semantic values, many with low token numbers, we grouped related high-priority semantic values (in the sense of Olátéjú 2005: 377) together. This resulted in the following semantic domains: ORGANISED WAR AGAINST OPPRESSION (e.g. captain, general, enemy), VIOLENCE (e.g. card, skin, thresh, burn), PROPER NOUNS (e.g. Tom Delany, Alexander), MORAL SUPERIORITY (e.g. fair play, justice, loyalty), HISTORICAL FIGURES (e.g. Bonaparte), PHYSICAL/MENTAL SKILL (e.g. Quickhand), IRISH NATIONALISM (e.g. Hibernicus) and LIGHT/DARKNESS (e.g. Starlight). Any remaining values that could not be grouped meaningfully and had less than three tokens were discarded. The domain PROPER NOUNS includes generic personal names and place names that could not be placed in any of the other categories. For example, Moll Doyle, though consisting of generic proper names, refers to a historical person and was thus placed in this domain instead.

\section{Semantic domains in the construction of threat}

A detailed analysis of the meaning-carrying elements of the 473 tokens in the corpus produces a fairly clear picture of the semantic domains accessed through the pseudonyms. All in all, these domains uncover underlying sociocultural categories and schemas that may be regarded as key to the sociocultural cognition of Irish people living through the era of agrarian violence in 19thcentury Ireland. As illustrated in Figure 1, the two most salient conceptual motifs in the pseudonyms ${ }^{1}$ are ORGANISED WAR AGAINST OPPRESSION $(\mathrm{N}=279)$ and VIOLENCE $(\mathrm{N}=261)$. Much less pervasive, but still rather frequent is the domain of PROPER NOUNS $(\mathrm{N}=122)$. The domains of

\footnotetext{
${ }^{1}$ Note that one pseudonym may access a number of semantic domains (see 3.2). Hence, the raw frequencies of the semantic domains exceed the number of pseudonyms in the corpus.
} 
MORAL SUPERIORITY $(\mathrm{N}=66)$, HISTORICAL FIGURES $(\mathrm{N}=46)$, PHYSICAL/MENTAL SKILL $(\mathrm{N}=24)$, IRISH NATIONALISM $(\mathrm{N}=18)$ and LIGHT/DARKNESS $(\mathrm{N}=17)$, albeit less frequent in relative terms, also contribute noticeably to the cognitive patterns underlying the forming of pseudonyms in our data.

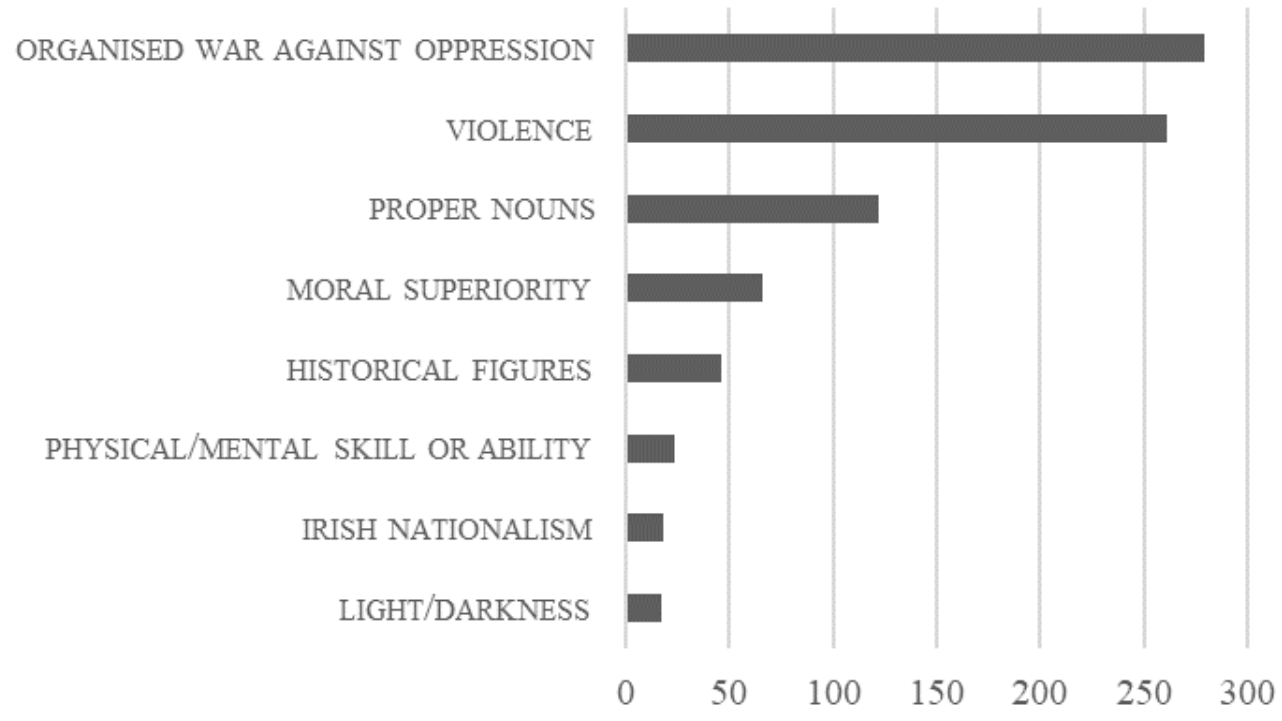

Figure 1. Semantic domains present in the pseudonyms (raw frequencies)

\subsection{Organised war against oppression}

The semantic domain of ORGANISED WAR AGAINST OPPRESSION includes the keywords in Table 1, and consists of references to a division of an army, or a body of troops regularly organised, both friendly and hostile ( $\mathrm{N}=11$, i.e. corps; OED, sv corps $\mathrm{n}^{1}$ and enemy; OED, sv enemy $\left.\mathrm{n}^{1},{ }^{2},{ }^{3}\right)$, a general British military order of chivalry and its Irish equivalent (Knight commander of the Bath and Knight of St Patrick, respectively, $\mathrm{N}=8$ ), and a wide variety of military ranks ranging from ensign to Commander-in-Chief $(\mathrm{N}=260)$. All of these lexemes portray the authors as part of an army, and the frequent use of commanding military ranks encodes an additional element of power, thus framing the author as someone who is in charge and who can give orders to lower ranks. Additionally, the lexemes involving military order activate cultural conceptualisations of chivalry and moral superiority, two elements that play an immense role in the ethical evaluation of the motivations for making threats.

Table 1. Lexemes in the ORGANISED WAR AGAINST OPPRESSION domain (Raw frequencies) 
$\begin{array}{ll}\text { Captain } & 197\end{array}$

General $\quad 40$

$\begin{array}{ll}\text { Enemy } & 9\end{array}$

Commander-in-Chief $\quad 5$

Knight Commander of the Bath 4

Knight of St Patrick $\quad 4$

Major $\quad 4$

Colonel 3

Corps 2

Marshall 2

Other: Commander (1), Ensign (1), General-Captain (1), Generalissimo (1), Lieutenant (1), 9 Lieutenant-Captain (1), Lieutenant-Colonel (1), Major-General (1), Sergeant (1)

None of the lexical items in this domain directly connote a theme of war in isolation. However, an approach that combines close reading of the notices with analyses of collocations and "extended keyword chains" (Peters 2017: 143), reveals that all of the lexical items generally involve one particular type of metonymic extension in which the PROFESSION OF A PERSON (captain or general) stands for the typical ACTIONS RELATED TO THE PROFESSION ('of or relating to warfare or defence'). In other words, notices where these pseudonyms are used often contain other lexemes that index war, as in Example (4). The author of the notice tries to stir up the Melesians to arms, that is, to prepare for battle. Melesians is also a war-reference, as they are named after the character Míl Espáine 'soldier of Hispania', who, in Irish mythology, were Gaels from Hispania who became the ancestors of all the Irish. The native Irish shall march, that is "to walk in a military manner with regular and measured thread" (OED, sv march $v^{2}$ ), and the author denotes himself as leading the army. Though Example (4) is an extreme case, many of the notices contain similar rhetoric.

(4) Arise, O Melesians; the day of our deliverance is coming, when the trumpet beats to arms - At Ardpatrick ye shall march, join us as your eyes shall have no pity on the breed of Luther [...] I will stir up the spirit of the antient Melicians against them [...] I will be at the head of an army of two hundred and forty thousand men [...] I am sir with the greatest respect the friend of the poor. Captain Rock and Storm (unknown, 05/01/1822, Limerick)

When an author uses a pseudonym that includes a military title or order of chivalry, they create a persona who, through sending the notice, acts either as a military commander of the addressee (for example in cases where a parish is cautioned not to pay tithes) or as one belonging to a hostile army, offering conditions of surrender (for example where an individual is ordered to fire a 
labourer from a different county, as all employment should go to locals). The pseudonym thereby activates a cognitive frame of warfare, and disobedience to commands, whether addressed to subjects or adversaries, will be punished. Activating the cognitive frame of an armed confrontation, pseudonyms involving conceptual knowledge of war contribute substantially to the severity and comprehensiveness of the threat, in which the target is constructed as the enemy, facing a maximally organised armed force. This semantic domain is the most frequently occurring one in the pseudonyms and thus a highly pervasive element in the construction of threat in the notices.

\subsection{Violence}

The second most salient semantic domain in the pseudonyms is VIOLENCE, which consists of 261 tokens, i.e. $55 \%$ of all pseudonyms contain a reference to violence. These references can be further subdivided into different types of violent acts, as shown in Table 2. The most frequent element is Rock (as discussed below), followed by the sub-domains HURTING SOMEONE WITH A SHARP INSTRUMENT, REFERENCES TO FIRE, TAKING A LIFE, HURTING SOMEONE WITHOUT AN INSTRUMENT, HURTING SOMEONE WITH A FIREARM, NATURAL VIOLENCE, blood, and finally rouse.

Table 2. Types of violence represented in the pseudonyms (raw frequencies)

\begin{tabular}{lc} 
Rock & 176 \\
HURT WITH (SHARP) INSTRUMENT (card, lash, skin, slash, thrash) & 27 \\
FIRE (fire, burn) & 13 \\
TAKING LIFE (kill, dead, breakneck) & 9 \\
HURT WITHOUT INSTRUMENT (thump, knock, rout, thrust, smash, skelp, shake) & 8 \\
HURT WITH FIREARM (shoot, blow brains, blunderbuss) & 5 \\
NATURAL VIOLENCE (storm, thunder) & 5 \\
Blood & 4 \\
Rouse & 4 \\
\hline Total & 261
\end{tabular}

The lexeme Rock is the most frequent element in this domain, and can be argued to be truly culturespecific to Ireland. With 176 tokens, it is a constituent of about one third (37\%) of all the pseudonyms in the TNC. It predominantly collocates with Captain (52), General (25), and John (23) - within a search horizon of two lemmas to the left - and refers to a somewhat mythical leader figure (and social movement, i.e. the Rockite movement). The origin of Captain Rock lies in the 
historically verifiable story of an uprising against English magistrate Alexander Hoskins by one Paddy Dillane of west Co. Limerick, in the early 1820s. Dillane had chased away some Englishmen who worked for Hoskins by throwing rocks and gravel at them and henceforth was called Carraig in Irish Gaelic or Rock in English by local people. When put on trial later for killing Hoskins' son, he referred to himself as Captain Rock (Donnelly 2009: 39-40), a pseudonym that evidently became key to one culture-specific aspect of the construction of both social identity and violent threat throughout the agrarian unrest of the 19th century.

From a cognitive sociolinguistic perspective, Rock could be regarded both as the outcome of metonymic extension (INSTRUMENT FOR USER) and as a sociocultural category in its own right as it involves a categorisation that provides a basic semantic framework in the sociocultural cognition of 19th-century Irishmen and Irishwomen experiencing agrarian violence in some way. A collocation analysis for Rock (with a search horizon of five lemmas left and right) in the TNC uncovers categorical schematic information that points clearly to how Rock is coded in the minds of the authors of the threatening notices and why, as a category, it is so widespread in constructing threat in the TNC. Frequent conceptualisations in the data are: (a) ROCK AS A SOCIAL, POLITICAL AND MILITARY LEADER ( $\mathrm{N}=56$ ), one who has loyal subjects (Studdart, 23/02/1822) and, as a commander, requests, requires, directs, conjures and commands (Ballyclough \& Drumdoney, 11/12/1821, Cork); (b) ROCK AS FRIEND and DEFENDER OF THE POOR ( $\mathrm{N}=25)$, whereby Rock is conceptualised as a friend of the addressee (e.g. Fair, 02/01/1823, Mayo), a friend of the poor (e.g. unknown, 05/01/1822, Limerick), or a defender of the Irish radicals (e.g. Mallow, 18/07/1822, Cork) - that is, Rock is portrayed as a type of morally superior socio-political avenger or retaliator; (c) ROCK AS A MYTHICAL FIGURE ( $\mathrm{N}=19)$, including ROCK IS RESIDING IN A MYTHICAL PLACE ( $=$ 12), such as Rock Castle by Moonlight (Ballclough, 11/12/1821, Cork) or Starlight Lodge (Killyflynn, 09/02/1822, Kerry) which add an element of nocturnal secrecy, and ROCK IS NOT DEAD/STILL ALIVE ( $=5$ ) (e.g. captain Rock is not dead yet Rush, 10/07/1869, Westmeath). Thus, the longevity of Rock as pseudonym allows the name to take on mythical connotations, not only within a short time span of the birth of Captain Rock, but as late as the $1860 \mathrm{~s}^{2}$ This proves that the underlying conceptualisations remained largely intact, i.e. were not subject to considerable cognitive renegotiation, ${ }^{3}$ and that the category underwent change only with a view to a metonymical extension along the lines of INDIVIDUAL INITIATOR OF AN ACTION FOR GROUP OF INITIATORS OF SIMILAR ACTIONS (Rock > Rockites).

Many of the categories and schemas yielded by the collocation analysis show how central the conceptualisation of Rock is to the agrarian conflict of the 19th century, and to some extent this conceptualisation is also mirrored in the semantic domains represented by the other pseudonyms in the TNC (e.g. moral superiority, violence, leader, light/darkness). This can be taken

\footnotetext{
${ }^{2}$ We acknowledge the possible conceptual interpretation of ROCK from a biblical-religious perspective. However, in our data, there is direct evidence for links with the original historical background only. It is possible that the biblical imagery might have added a layer of interpretation, in particular for those later adopters of the pseudonym who were unfamiliar with the original back-story, but there is no evidence whatsoever for this interpretation in our data.

${ }^{3}$ On the notion of "renegotiation of cultural conceptualisations", see, e.g. Sharifian (2011: 5) and Peters (2017: 140143).
} 
as emphasising the fact that there are underlying cognitive patterns in the construction of disguise and threat through the pseudonyms in the data.

The majority of lexemes from the semantic domain of VIOLENCE involve a metonymic shift whereby the ACTION OF A PERSON (e.g. carding, skelping, thumping, etc.) stands for the PERSON (somebody who cards, skelps, thumps, etc.). Blunderbuss on the other hand makes use of a metaphorical mapping through the semantic and conceptual structure 'object capable of hurting/killing someone' from one conceptual domain (OВJECT: blunderbuss) to a different domain (PERSON: Captain Blunderbuss). A similar process is required for the pseudonyms involving natural violence, such as Captain Thunder, Captain Thunderbolt and Captain Storm. Here the structure 'violent disturbance, destruction' is mapped from the domain ATMOSPHERE to PERSON.

The lexeme blood, found in the pseudonyms Timothy Bloodsucker and Bloodshed, is particularly interesting as it involves two layers of cognitive processing. First, the actions bloodsucking and bloodshedding, which both rely on the conceptual metaphor BLOOD IS LIFE, require decoding; the structure 'condition, quality or fact of being a living person' is mapped from LIFE onto BLOOD, where the possession of blood equates the same properties of 'being alive', whereas loss of blood signifies the end of life. Once this metaphor is decoded, it can be metonymically extended from ACTION OF PERSON (sucking blood, shedding blood) to the PERSON.

A further kind of "natural" violent disturbance is accessed through the conceptual domain of FIRE, referenced by pseudonyms such as Captain Fireball $(\mathrm{N}=4)$, Captain Firebrand $(\mathrm{N}=2)$, Captain Fire Smith $(\mathrm{N}=1)$, Captain House Burner $(\mathrm{N}=1)$ and Catherine Sparks $(\mathrm{N}=1)$. As many notices in the TNC mention violence involving fire, especially the burning of the recipient and/or his family and/or property, the pseudonyms access conceptualisation patterns based on the conceptual metaphor FIRE IS ANIMAL, where, in a metonymic pars-pro-toto relationship, FLAMES CONSUME AND DEVOUR. In accessing this widespread conceptual metaphor in their pseudonyms, the authors construct themselves as not only possessing human powers but also as being capable of commanding natural forces that are animalistically brutal, if not even somewhat arcane and mysterious, and to some degree unpredictable and unstoppable.

Overall the lexemes in this domain connote general violent acts, such as kill, shoot, or thrust, but some of them are more context-specific, not necessarily specific to the Irish context per se, but specific to an agrarian lifestyle, such as the act of carding and accompanying pseudonyms such as Murty the Carder (O'Rorke, 30/06/1817, Leitrim). A similar case concerns pseudonyms containing the lexeme thrash, which originally meant "to separate by any mechanical means, e.g. rubbing, shaking, trampling, stamping, beating, or intermittent pressure, the grains of any cereal from the husks and straw" (OED, sv thrash/thresh, v1, I1) and later became metaphorically extended to "beat by way of punishment, to chastise by or as by beating; to flog, orig. with a stick, cudgel, whip, etc." (OED, sv thrash/thresh, v1, II5a).

As a basic principle, the use of metaphoric transfer and metonymic extension in the domain of violence allows authors to foreground the forceful side of their identities and use it to intimidate addressees. They portray themselves as personae who commit these violent acts so frequently that they embody the violent act, regardless of whether they have ever actually hurt somebody. Thus, 
the pseudonyms access categorical and schematic knowledge in relation to human and natural violence, including the many ways in which bodily harm can be inflicted on a person, which activates a very concrete cognitive frame of exposure to threat. This frame relies on the one hand on conceptualisations of the outside world that are shared across a number of (western) cultures, e.g. knowledge of farming and production techniques, the functions of tools and weapons and a shared perception of laws of nature. On the other hand, it relies on cultural categories and schemas that are specific to the Irish context, as aptly demonstrated for the highly frequent pseudonym Rock, which entails a range of conceptual patterns that are inaccessible for anyone from outside the cultural group experiencing the agrarian violence of 19th-century Ireland.

\subsection{Proper nouns}

In addition to the use of titles related to military ranks and violent elements, many of the pseudonyms make use of personal names commonly found in Ireland $(\mathrm{N}=122)$. They could be first name only, such as a notice signed by Jack, Paddy and Joseph $(\mathrm{N}=3)$, first name and surname such as Peter Bulwagins $(\mathrm{N}=7)$, or a modifier followed by a surname $(\mathrm{N}=3)$, but most common is a first name with a further modifying element such as John the deliverer $(\mathrm{N}=77)$. Some of the names included here may have had some local significance at the time, but from today's perspective we were unable to identify an obvious historical person who might have acted as referent for pseudonyms in this category.

The use of a common personal name serves to create the impression of a physical presence behind the threat, and as they are common, the implication is that they are realistic; the author could literally be anyone. These names can also foreground certain identity aspects. For example, common English first names such as Catherine, Henry, or Jack, and surnames (e.g. Dorsey or Fanshaw) all stem from a general English cultural-cognitive system of naming practices. The names Murty, Paddy, Patrick and Shaune and the surnames Culloon, Delany, Ferrell, and O'Brine, on the other hand, encode a more specifically Irish-English cultural identity. The first names and the titles used to modify some of the surnames also ascribe a specific gender to the persona attached to the pseudonym, which is predominantly male, Catherine being the only exception.

In addition to the use of personal names to create a gendered, general English or specifically Irish-English identity, references to place names or locations are also found among the dataset, though not very often $(\mathrm{N}=19)$. These pseudonyms include Lady/Captain/the honourable Clare, Tommy Downshire, or Tipperary boy. In most cases the place name corresponds closely to the county in which the notice is sent. It is thus likely that in these cases the place name offers some biographical information and foregrounds the authors' geographical roots, i.e. they clearly wish to assert themselves as (relatively) local to the area and thus having an interest in the local affairs addressed in the notices. Simultaneously, place names always activate conceptualisations of local

social networks and/or communities of practice and thus strongly frame the contrast between the local vis-à-vis the non-local, the in-group vis-à-vis the out-group and rightful (locally-rooted) 
behaviour vis-à-vis the unrightful (locally-imposed) misbehaviour. All these contrasts are tightly interwoven with aspects of moral superiority and Irish nationalism, which are discussed in detail under 4.4 and 4.7 below.

Sometimes there is no correspondence at all, but in these cases the place name in the pseudonym often refers to a "secret society" known to be active in the region specified and has now also started to operate in the region where it was posted. For example, the Tipperary Whiteboys, who were mainly active during the first half of the 19th century, spread their activity to Westmeath in the late 1860s (Byrne, 21/04/1869, Westmeath and Mannsell, 24/09/1869, Westmeath). In these cases, the pseudonym does not necessarily foreground the author's local origins, but rather activates schematic knowledge of violence that occurred in a particular location.

\subsection{Moral superiority}

Though ORGANISED WAR AGAINST OPPRESSION and VIOLENCE are the most pervasive semantic domains in the pseudonyms, the authors of the notices do not just mean to instil fear in their targets through their choice of pseudonym, but also to justify their own actions to the public and describe themselves as morally superior $(\mathrm{N}=66)$. Pseudonyms such as a friend, Captain Cautioner, John Goodwill, or Captain John Speedwell ${ }^{4}$ set up the author as a person who has the best interest of the addressee at heart and is offering advice or warning rather than threat.

Pseudonyms such as Mr Fair Play, a lover of justice, and enemies to oppression take it one step further and allow the author to claim the moral high ground vis-à-vis the addressee. The personae are not acting in their own interests, but out of a sense of justice and righteousness. They feel the need to make the world a better place, as evidenced through the use of pseudonyms such as captain conscience, Veritas, or Friends of Liberty, and they do not fight for themselves but for the people, as expressed through pseudonyms such as the friend of Orphans and Captain to the Poor. The use of elements related to MORAL SUPERIORITY thus allows for a kind of positive selfdescription by the author of the text, where s/he draws the attention of the reader(s) to their moral intentions.

\subsection{Historical figures}

In addition to common Irish personal names without clearly identifiable referents, the authors of the notices sometimes also chose a well-known historical figure as their pseudonym $(\mathrm{N}=46)$. For example, three notices mention Bonapart (1769-1821), as an enemy of the English, and one notice was signed using nine different pseudonyms related to the French Revolution (1789-1799) and the Reign of terror (1792/3-1794): Marat, Robespierre, Brissot, Petion and Barrere, DANTON, St

\footnotetext{
${ }^{4}$ Speedwell is a plant named after the blessing speed you well 'may you be successful in your endeavours' (OED, sv speedwell, $n$ ) and was sewn into clothes in Ireland to ward against accidents (Plantlife 2018: speedwell).
} 
Just, Condorcet, and Roland. The use of these pseudonyms allows for the transfer of schematic and categorical knowledge of the concept of SUCCESSFUL REVOLUTION from one context to another, contributing to the conceptualisation of a threatened revolt against the established order for the better of the people. The choices of St Just, Robespierre, and Barrere in particular contribute to the threat, considering their roles in the Reign of Terror, a period during the Revolution when terror was advocated as appropriate means against enemies of the Revolution through mass executions. The revolutionary, anti-establishment interpretation is supported by the content of the notice, which mentions conceptual key notions such as revolutionary principles, shaking off the yoke, and rise (en masse).

It is not only French revolutionaries that are used to cognitively trigger the threat of revolution, but also Irish ones. The most frequently used pseudonym referring to an Irish revolutionary is Rory of the Hill $(\mathrm{N}=13)$, followed by Moll Doyle $(\mathrm{N}=10)$ and finally Maguire $(\mathrm{N}=2)$. The pseudonyms Rory of the Hill/Red Rory the mountain war captain and Captain Maguire/Mary Maguire eldest son refer to Rory O'Moore and Connor Maguire (and his wife Mary) who played a significant role in the failed Irish Rebellion of 1641, invoke the spirit of those who fought in it, and carry connotations of revolution against the administration and violent massacre of protestant settlers. Moll (and the variant forms Mary Doyle, sons of Moll Doyle, and Doils) refers to a movement or "secret society" named after a notoriously fierce female combatant in the failed Irish Rebellion of 1798 (O'Connor 2003: 96). Again, use of this pseudonym allows the author to borrow connotations of revolution, bravery, and violence from the person who originally created this identity for herself through her actions, i.e. the original Moll Doyle.

However, it is not just famous warriors or military leaders whose spirit is kept alive and transferred to the authors of the threatening notices. The pseudonym Terry Alt $(\mathrm{N}=9)$ is used to refer to a movement named after a protestant army pensioner and loyalist, which seems an odd identity to adopt, considering he is a member of the subculture most of the authors oppose, and thus highly unlikely to be involved with agrarian factions. In this case, a local group from Clare seems to have picked up on a case of mistaken identity; the innocent Terry Alt had supposedly stumbled on a crime scene and was dressed similarly to how the victim described the assailant; hence, he was facetiously accused of the crime. This joke was picked up by a local agrarian faction who adopted the habit of crying out Well done, Terry! Well done, Terry Alt! every time they had committed an outrage and soon adopted the name Terry Alts (Clare Museum 2002). Thus, in this case it is not the true identity of the man behind the orthonym that is being passed on and kept alive, but collectively shared associations with the identities behind previous users of the pseudonym.

Overall, pseudonyms from the semantic domain of HISTORICAL FIGURES, such as Rory of the Hill, Moll Doyle and Terry Alt, show similar degrees of sociocultural embedding and create context-specific threat through accessing socio-historical knowledge shared by members of the Irish English speech community at the time of writing. 


\subsection{Physical/mental skill or ability}

Some of the pseudonyms also have an element that foregrounds certain abilities, character traits or skills. The most common trait the authors choose to foreground is their bravery. Pseudonyms such as (Captain/John/Sergeant) Fearnot ( $\mathrm{N}=5)$, brave (and powerful) Captain Rock, Rock the valiant knight of St Patrick all metonymically extend the concept of 'bravery' to the author of the letter, and considering they are all portrayed as military leaders occupied with the business of war, bravery is deemed indispensable. In addition, a fearless threatener is more intimidating than a scared one. The same argument can be made for the concept of strength in pseudonyms such as Captain Steel(ribs) $(\mathrm{N}=4)$ and Lieutenant Lion, which are rooted in the underlying conceptual metaphor PHYSICAL STRENGTH/STABILITY IS EMOTIONAL STRENGTH/STABILITY (see Kövecses 2015: 9). In a similar vein, pseudonyms such as B Strong and D.S. Power rely on metonymical extension (PROPERTY OF PERSON FOR PERSON) in order to highlight strength. Bravery and strength are the most common abilities found in the pseudonyms, but other abilities and skills are represented as well, such as 'invisibility' (Captain of the invisible core, Captain hide), 'untiring' (Jack Late \& Early, ${ }^{5}$ the indefatigable Sir John Rock), 'nimbleness' (Captain Lightfoot, Captain Nimble), 'smart' (Captain Thinkwell), and 'skilled/fast writer' (Simon Quickhand Sec.). ${ }^{6}$ Thus, the pseudonym highlights personal qualities that are perceived as valuable to the persona they characterise and arguably contribute to a positive self-description of the author.

\subsection{Irish Nationalism}

The semantic domain of Irish nationalism is invoked in eighteen pseudonyms, in various ways. The most direct invocation is probably the pseudonym The Brotherhood $(\mathrm{N}=1)$, which by 1869 was well-known for its nationalist sympathies. Juxtaposition of the Irish against the English, however, is a more frequent mechanism to construct the concept of nationalism. The lexemes Irish and Ireland $(\mathrm{N}=10)$ in some of the pseudonyms juxtapose the Irish, represented by the author, against the English and those loyal to them, embodied by the addressee. This is done through the descriptive labels that accompany the pseudonym Captain John Rock who is Captain of the Queen Green Leavelers of Ireland, or a military leader of Ireland, the United Irishmen, the Irish forces, the Irish Patriots, and the Irish Radicals. The pseudonym Radical council of Ireland and the personification of Ireland as a nation in the pseudonym Hibernicus, the Latinate name for an inhabitant of Ireland $(\mathrm{N}=1)$, also foreground an Irish identity vis-à-vis an English or United

\footnotetext{
${ }^{5}$ The nickname Late \& Early has been known to be ascribed to people who work till late in the evening and start again early in the morning.

${ }^{6}$ Another interpretation of Quickhand could refer to the speed with which the author is able to draw a pistol and shoot someone. However, the post-modifier Sec, as well as a reference to 'he [General Joseph Justice] desired me with rapidity Issue this proclamation' in the main body of the notice, make it clear that he is indeed playing the part of a secretary and makes the 'quick writing' interpretation more parsimonious.
} 
Kingdom identity. The specific inclusion of the lexemes Irish and Ireland emphasise the fact that the authors are championing the Irish people only and seem to suggest that Ireland is an independent nation which has its own army and its own governing body.

The use of the Irish language, or reference to it, signals Irish nationalism in a similar way. For example, one of the notices is undersigned Fitz \& Mac Secretaries, both of which mean 'son' in Norman French and Irish Gaelic, respectively, and are commonly used prefixes in the formation of surnames. The use of the Irish prefix Mac allows for the interpretation of 'son of Ireland', where the Irish language stands for Ireland as a whole. The use of Fitz is less straightforward, but this particular naming practice was introduced to Ireland by the Anglo-Normans in the twelfth century, who later became Gaelicised and from the late 16th-century onwards joined the native Irish and fellow Catholics in their fights against the "new", protestant English. Thus, Fitz could be seen here as "old" English as opposed to the "new" English who were seen as the enemy (see OED, sv Fitz, $n$ ). The rival groups Caravats and Shanavests were also embodied in the pseudonyms in the form of Captain Shanavest and I of the Carovats. The Shanavests were prosperous farmers who resisted outrages carried out by a particularly violent agrarian faction, called the Caravats, but according to Connolly (2007) they had ties with the former United Irishmen, who led the 1798 Rebellion. Caravats has been claimed to come from Irish Gaelic Carabhaití 'neck cloth, scarf, tie' which could be metaphorically extended to mean 'noose', and Shanavests is an anglicised form of Irish Gaelic Seanabheastaí 'old coats' (Gash 1961). Thus, ties with the 1798 Rebellion and the use of the Irish language encode a sense of Irish nationalism.

Pseudonyms from the semantic domain of IRISH NATIONALISM thus contribute to the threatening message of the notice through the creation of culture-specific threat as a result of the foregrounding of an Irish identity and connotations of the 1798 Rebellion. Only the emic perspective allows capturing the full extent of the threats contained in the pseudonyms.

\subsection{Light/darkness}

Semantic elements relating to light and darkness are also found in the pseudonyms. There are a total of seventeen pseudonyms that make use of the lemmas starlight $(\mathrm{N}=10)$, moonlight $(\mathrm{N}=3)$, sunshine $(\mathrm{N}=1)$, daylight $(\mathrm{N}=1)$, nocturnal parties $(\mathrm{N}=1)$, and night errant $(\mathrm{N}=1){ }^{7}$ Thus, the vast majority of these refer to night-time $(\mathrm{N}=15)$, and as such construct an identity as nocturnal creatures, individuals who are used to travelling in darkness and conducting their business by stealth.

References to night-time seem to aid in the construction of threat by addressing a range of associated cultural conceptualisations, such as the widespread human fear of the dark and a number of emotions connected with it (cf. Marks 1969: 106-7). These conceptualisations of darkness and night-time are intrinsically negative, which can be seen, for example, in the non-culture-specific

\footnotetext{
${ }^{7}$ It could be argued that night errant is a misspelling for knight errant, but the style, grammar and spelling of the rest of the notice suggests the author had an above average level of education and it is more likely to be a clever wordplay.
} 
and widespread conceptual metaphor DEATH IS NIGHT (Kövecses 2002: 48-49). To give an example from the Irish context, night-time references may invoke the Celtic belief of one day ending at sunset and the next one only starting at sunrise. All the intermediate time thus belongs to mythical creatures like fairies and banshees, exhibiting all sorts of frightening and potentially lifedetermining behaviours under the cover of darkness (see Peters 2017). In 19th-century Ireland, fear of the dark not only involved the fear of encounters with "non-human elements" (Brands et al. 2015: 439), but rather a fear of crime committed by fellow humans. The underlying emotions of vulnerability and exposedness due to the absence of both natural and artificial light are intensified by this fear of nocturnal violence and death. Both fear and intensification function on the grounds of cultural cognition as well as individual cognition as they access both communal and individual "habit-memory", i.e. "cognitive thought about the range of immediate futures that might unfold" (Brands et al. 2015: 443), based on community-wide and personal experiences in the past. With their explicit references to night-time, the authors of the threatening notices thus access a multi-layered psychological system, including both the FEAR OF NIGHT, FEAR OF DARK and the FEAR OF CRIME cognitive schemas.

\section{Conclusion}

In our analysis of 473 pseudonyms, we have identified eight semantic domains that are accessed recurrently in order to contribute to the notion of threat, i.e. ORGANISED WAR AGAINST OPPRESSION ( $\mathrm{N}=279)$, VIOLENCE $(\mathrm{N}=261)$, PROPER NOUNS $(\mathrm{N}=122)$, MORAL SUPERIORITY $(\mathrm{N}=66)$, HISTORICAL FIGURES $(\mathrm{N}=46)$, PHYSICAL/MENTAL SKILL $(\mathrm{N}=24)$, IRISH NATIONALISM $(\mathrm{N}=18)$ and LIGHT/DARKNESS $(\mathrm{N}=17)$. These semantic domains show that contributing to the notion of threat in 19th-century Irish English threatening communication not only involves menacing war, violence, darkness and perdition directly, but also entails constructing a certain persona for the threatener him-/herself that highlights their motivation, their moral superiority, their historical, local and circumstantial expertise, and their physical and mental aptitude, all of which in the end augment the perception of threat on the part of their targets. Thus, pseudonyms turn out to be polysemic and multifaceted, and considering that they are often intended to trigger a reaction, pseudonyms arguably construct a frame which helps the audience interpret the communicative event in which the pseudonym is employed (Maleej et al. 2016: 15). The notion of frames here can be understood as "principles of organisation which govern events - at least social ones - and our subjective involvement in them" (Goffman 1974: 155) and as "mental structures that shape the way we see the world" (Lakoff 2004: xv).

It is noteworthy that the pseudonyms in our data mostly appear at the very end of each threatening notice and hence function as what we will call post-positioned semantic frame setters. The multifaceted identities constructed within the pseudonyms provide a lens through which the audience views the entire previous letter. For example, a note saying Have you seen your daughter lately? will be interpreted differently depending on the type of semantic lens provided by the 
pseudonym in the signature. If the letter is undersigned with the orthonym of a person the recipient knows well, it will probably be interpreted as someone enquiring how the daughter is doing. However, if the note is signed with a pseudonym such as Murty the Carder, Colonel Thresher or John Rocke Generalissimo of the Irish Radicals, the note will be interpreted as a threat. Thus, pseudonyms and the polysemic identity and meaning-carrying aspects they may contain, function as post-positioned frame setters, i.e. cognitive lenses through which recipients interpret the messages conveyed. As shown in our analysis of semantic domains, the most prominent lens provided by pseudonyms in the act of threatening in the TNC is that of an organised war against oppression - whether via illegitimate British rule or tyrannical/selfish landlords - comprising conceptualisations of WAR, VIOLENCE, MORAL SUPERIORITY and IRISH NATIONALISM.

Secondly, our analysis shows that pseudonyms contribute to the deontic force of the threatening notices in that they increase the intended perlocutionary effect of the entire previous letter, i.e. that of creating threat and instilling fear in order to get the recipient to behave in accordance with the demands made in the threatening note. By constructing types of personae through activating widely shared cultural conceptualisations of, e.g. revolution, warfare, violence, death, pain, etc., pseudonyms create a very real presence behind a threat. Simultaneously, through the use of common names, titles and labels, the pseudonyms suggest that the threatener could be anyone from the (local) community, hence increasing the threat through accessing cognitive schemas pertaining to MYTHICAL FIGURES, FEAR OF THE DARK, VIOLENCE and REVOLUTION.

Thirdly, our analysis demonstrates that pseudonyms can be, though need not be, contextspecific in that they may draw from a number of semantic domains that are relevant within a specific sociocultural group with a shared sociocultural cognition. Social context-specificity in our data seems to be attached to agrarian themes in the broader sense, whereas cultural contextspecificity seems to pertain to conceptualisations of Irish nationalism and the cultural category of ROCK in particular. In the creation of pseudonyms such as Rock, local geographical areas, places, names, events and emotions contribute greatly to schematisation patterns that distinctly represent 19th-century rural Ireland.

\section{Sources}

Gibbons, Stephen Randolph. 2004. Captain Rock, Night Errant - The Threatening Letters of PreFamine Ireland, 1801-1845. Dublin: Four Courts Press.

\section{References}

Aceto, Michael. 2002. "Ethnic personal names and multiple identities in Anglophone Caribbean speech communities in Latin America". Language in Society 31, 577-608. 
Agha, Asif. 2005. "Voice, footing, enregisterment". Journal of Linguistic Anthropology 15, 3859.

Blanco Salgueiro, Antonio. 2010. "Promises, threats, and the foundations of speech act theory". Pragmatics. Quarterly Publication of the International Pragmatics Association 20, 213-228.

Brands, Jelle, Tim Schwanen, and Irina Van Aalst. 2015. "Fear of crime and affective ambiguities in the night-time economy". Urban Studies 52, 439-455.

Brinkman, Inge. 2004. "Languages, names, and war: The case of Angola". African Studies Review 47, 143-163.

Clare Museum. 2002. "The Terry Alts." Clare Champion 15 Nov. 2002. <http://www.clarelibrary.ie/eolas/claremuseum/news_events/terry_alts.htm> (accessed September 28, 2018).

Connolly, Sean J. 2002. "Caravats and Shanavests". In Sean J. Connolly, ed. The Oxford Companion to Irish History. Oxford: Oxford University Press. <http://www.oxfordreference.com/view/10.1093/acref/9780199234837.001.0001/acref9780199234837-e-249> (accessed March 15, 2018).

Davis, Dennis A. 1997. Threats Pending Fuses Burning: Managing Workplace Violence. Palo Alto: Davies-Black Publishing.

Dietz, Park Elliot, Daryl B. Matthews, Daniel Allen Martell, Tracy M. Stewart, Debra R. Hrouda, and Janet Warren. 1991. "Threatening and otherwise inappropriate letters to members of the United States Congress". Journal of Forensic Science 36, 1445-1468.

Dobrić, Nikola. 2010. "Theory of names and cognitive linguistics: The case of the metaphor". Filozofija i drustvo 21, 135-147.

Donnelly, James S. jr. 2009. Captain Rock - The Irish Agrarian Rebellion of 1821-1824. Madison: University of Wisconsin Press.

Felus, Antoni. 1990. "Situational aspects of pseudonyms”. Forensic Science International 46, 6975.

Fraser, Bruce. 1998. “Threatening revisited”. Forensic Linguistics 5, 159-173.

Gales, Tammy. 2011. "Identifying interpersonal stance in threatening discourse: An appraisal analysis". Discourse Studies 13, 27-46.

Gash, Norman. 1961. Mr Secretary Peel: The Life of Sir Robert Peel to 1830. Harlow: Faber and Faber.

Guenther, Katja M. 2009. "The politics of names: Rethinking methodological and ethical significance of naming people, organizations, and places". Qualitative Research 9, 411-421.

Hickey, Raymond. 2007. Irish English: History and Present-Day Forms. Cambridge: Cambridge University Press.

Jucker, Andreas H. 2009. "Speech act research between armchair, field and laboratory: The case of compliments". Journal of Pragmatics 41, 1611-1635.

Kallen, Jeffrey. 2017. Irish English: Volume 2 - The Republic of Ireland. Berlin: De Gruyter Mouton.

Kövecses, Zoltán. 2002. Metaphor - A Practical Introduction. Oxford: Oxford University Press. 
Kövecses, Zoltán. 2015. Where metaphors come from: Reconsidering context in metaphor. New York: Oxford University Press.

Kövecses, Zoltán, and Günter Radden. 1998. "Metonymy: Developing a cognitive linguistic view". Cognitive Linguistics 9, 37-78.

Lakoff, G. (2004). Don't think of an elephant: Know your values and frame the debate. White River Junction: Chelsea Green Publishing.

Lakoff, George, and Mark Johnson. 1980. Metaphors we live by. Chicago: The University of Chicago Press.

Livia, Anna. 2004. "Public and clandestine: gay men's pseudonyms on the French Minitel". Sexualities 5, 201-217.

Maleej, Zouheir, Mohammed Alghbban, and Sami Ben Salamh. 2016. "The Fragrance of Flowers', or Metaphoric and Metonymic Pseudonyms". Metaphor and Symbol 31, 212-229.

Makoni, Busi. 2016. "Labelling black male genitalia and the 'new racism'". Gender \& Language $10,48-72$.

Marks, Isaac M. 1969. Fears and Phobias. New York: Academic Press.

Muschalik, Julia. 2018. Threatening in English. A mixed method approach. Amsterdam: John Benjamins.

Newell, Stephanie. 2010. "Something to hide? Anonymity and pseudonyms in the colonial West African press". The Journal of Commonwealth Literature 45, 9-22.

Nini, Andrea. 2017. "Register variation in malicious forensic texts". International Journal of Speech, Language and the Law 24, 67-98.

O'Connor, Catherine. 2003. "The experience of women in the rebellion of 1798 in Wexford". The Past: The Organ of the Ui Cinsealaigh Historical Society 24, 95-106.

Ó Cuiv, Brian. 1986. "Irish language and literature, 1681-1845". In Theodore William Moody, and William E. Vaughan, eds. A New History of Ireland, Volume IV. Oxford: Oxford University Press, 374-423.

Ọlátẹjú, Adéṣọlá. 2005. "The Yorùbá Animal Metaphors: Analysis and Interpretation”. Nordic Journal of African Studies 14, 368-383.

Peters, Arne. 2017. "FAIRIES, BANSHEES, and THE CHURCH: Cultural conceptualisations in Irish English". International Journal of Language and Culture 4, 127-148.

Polzenhagen, Frank, and Hans-Georg Wolf. 2017. "World Englishes and cognitive linguistics". In Markku Filppula, Juhani Klemola, and Devyani Sharma, eds. The Oxford handbook of World Englishes. Oxford: Oxford University Press, 147-174.

Room, Adrian. 2010. Dictionary of Pseudonyms: 13,000 assumed names and their origins. Jefferson: McFarland.

Searle, John R. 1975. “A taxonomy of illocutionary acts”. In Keith Gunderson, ed. Language, Mind and Knowledge. Minneapolis: University of Minnesota Press.

Sharifian, Farzad. 2011. Cultural conceptualisations and language. Amsterdam: John Benjamins. Sharifian, Farzad. 2015. "Cultural linguistics and World Englishes". World Englishes 34, 515532. 
Smith, Sharon S. 2008. "From violent words to violent deeds? Assessing risk from FBI threatening communication cases". In J. Reid Meloy, Lorraine Sheridan, and Jens Hoffmann, eds. Stalking, Threatening, and Attacking Public Figures: A Psychological and Behavioral Analysis. New York: Oxford University Press, 435-455.

Solan, Lawrence M., and Peter Tiersma. 2005. Speaking of Crime: The Language of Criminal Justice. Chicago: Chicago University Press.

Thompson, Edward P. 1975. "The crime of anonymity". In Douglas Hay, Peter Linebaugh, John G. Rule, E. P. Thompson, and Carl Winslow, eds. Albion's Fatal Tree. Crime and Society in Eighteenth-Century England. London: Allen Lane, 255-344.

Turner, James T., and Michael G. Gelles. 2003. Threat Assessment: A Risk Management Approach. New York: Haworth Press.

van Hattum, Marije. 2017. "The language of 'Ribbonmen': A CDA approach to identity construction in 19th-century Irish English threatening notices". Journal of Historical Sociolinguistics 3, 241-262.

Walton, Douglas. 2000. Scare Tactics: Arguments that Appeal to Fear and Threats. Dordrecht: Springer.

Whelehan, Niall. 2012." Labour and agrarian violence in the Irish midlands, 1850-1870". Saothar 37, 7-17.

Wolf, Hans-Georg, and Frank Polzenhagen. 2009. World Englishes: A Cognitive Sociolinguistic Approach. Berlin: De Gruyter Mouton.

Authors' addresses

(Corresponding author)

Arne Peters

Institut für Anglistik und Amerikanistik

University of Potsdam

Am Neuen Palais 10

14469 Potsdam, Germany

arne.peters@uni-potsdam.de

Marije van Hattum

School of Arts, Languages and Cultures

The University of Manchester

Oxford Road

Manchester, M13 9PL, United Kingdom

marije.vanhattum@manchester.ac.uk 